\title{
THE STUDY OF KINEMATIC GNSS SURVEYING FOR BIM GEOREFERENCING
}

\author{
R. Akhmetov ${ }^{1}$, G. Makhmetova ${ }^{1}$, E. Orynbassarova ${ }^{1}$, A. Baltiyeva ${ }^{2}$, A. Togaibekov ${ }^{3}$, K. Roberts ${ }^{4}$, A. Yerzhankyzy ${ }^{1}$ \\ ${ }^{1}$ Satbayev University, Kazakhstan; r.akhmetov@ satbayev.university, g.makhmetova@satbayev.university, \\ e.orynbassarova@satbayev.university; a.yerzhankyzy@satbayev.university, \\ ${ }^{2}$ National Center on Complex Processing of Mineral Raw Materials of the Republic of Kazakhstan, Kazakhstan; \\ a.baltiyeva@gmail.com \\ ${ }^{3}$ University of Grenoble Alps, France; anuar.togaibekov@univ-grenoble-alpes.fr \\ ${ }^{4}$ University of Technology, Jamaica; kenielroberts@gmail.com
}

Commission V, WG V/7

KEY WORDS: Global Navigation Satellite Systems (GNSS), kinematic survey, bucket test, accuracy, georeferencing, precision positioning

\begin{abstract}
:
Building Information Modeling is a tool for creating, presenting and managing building data. The use of BIM has the advantage of obtaining greater detail and fidelity in design, construction and operation, increases efficiency, and serves as a digital transformation of the construction industry. As BIM continues to evolve and integrate, needs accurate spatial georeferencing is needed as a way to correctly display a model without changing the underlying data. The great common tool for referencing is GNSS. Having in mind tight surveying conditions for urban territories. It is preferable to use kinematic surveying mode. This study is an analysis of field measurements aimed at investigating the problem of GNSS accuracy under various adverse operating conditions. Every year, new updated receiver models and software versions appear on the geodetic market, so it is necessary to study their effectiveness and given accuracy. This paper shows information about a kinematic survey performed in a canopy, multipath and in an open area to evaluate the performance of the user segment of various manufactures.
\end{abstract}

\section{INTRODUCTION}

Nowadays, the use of GNSS systems is an integral part in positioning tasks. For various tasks, the required measurement accuracy exists, so different strategies are used to determine the solution of the position. GNSS systems receive signals from a large number of satellites, however, the signals are distorted, which leads to measurement errors that degrade positioning accuracy (Hofmann-Wellenhof, B., Wasle, H.L, 2008; Leick, A.,etal., 2015; Parkinson, B.W.; Spilker J. J. Jr, 1996). There are a number of GNSS errors that affect accuracy, some of them are insignificant, while others can give an error of up to a meter (Karaim etal., 2018; Grejner-Brzezinska, D.A.; etal., 2005). . The use of GNSS systems in urban environments is limited, since in a densely populated city with a developed infrastructure, where a large percentage of high-rise buildings, geometry errors occur that ultimately affect the measurement accuracy (Kubo N. and Dihan C., 2014; L.-T. Hsu, 2018) The main objective of the work was to analyze the accuracy assessment of GNSS systems. Since one of the most important requirements for the production of high-precision geodetic work using GPS equipment is good radio visibility at all designated points, which is provided by the following factors: low PDOP, high signal-to-noise ratio, radio signal quality and no loss of whole cycles upon admission radio signal, you need to consider these factors in advance (Jansson, P.; Persson, C.G., 2013.; Li, B.; etal., 2008). This paper we conducted three series of experiments by complex research of GNSS accuracy for mobile kinematic and kinematic bucket test in order to determine the influence of various site on the accuracy of the determination of

coordinates using GPS receivers. GNSS kinematic surveying is used to quickly and efficient approach to collect a large number of highly accurate geodetic coordinates (Satirapod, C., Wang, J. 2000; Wang, J., etal, 2005) The kinematic method is preferable to use in urban areas, especially in tasks where a quick solution is needed to obtain a set of points (Wang, L., etal., 2016). An example of the use of such technology is spatial georeferencing for building information modeling. An example of the use of such technology is spatial reference for building information modeling. A huge amount of research has been devoted to the issue of building information modeling over the past decade (Smith P. 2014.; Zhu J., Wu P., 2021) Features of the concept and interaction of BIM, as well as the exchange of digital data based on geospatial data analysis, are very accurately described in the work (Jaud, Š. etal., 2020). Digital BIM methods are being actively introduced, displacing computer-aided design (CAD) methods, building information modeling is effective in all construction life cycles. The technology for creating a BIM begins with obtaining data containing its location and orientation on Earth. Geospatial references provide an initial state model (basics) for design processes.

\subsection{Mobile Kinematic Tests}

The three GNSS receivers were used to collect data on open and canopy site were chosen to execute the kinematic tests. Javad external antenna was mounted on a trolley which contained other equipment including the splitter which facilitates the connection of the GS10 and Triumph-1 receivers to the same antenna. The track was circled 11 times. For the first five laps the receivers were configured to observe signals from both GPS and GLONASS satellites and GPS only for another five laps. For the eleventh lap the Javad receiver was configured to observed signals form only the GLNOASS constellation, while the GS10 was switched off.

\subsection{Bucket Test}


The bucket tests were done on canopy site and on the open site using the GS10 and Triumph-1 receivers. Two points were established on each site. On both sites two persons covered each receiver with iron buckets at the same time for 30 seconds, while the other two keep and record the time it took the receiver to acquire first fixed after the buckets were removed. This process was repeated 20 times in the open area. However this sample size was difficult to attain simultaneously on the canopy site. Thus during the occupation time for this site only 3 concurrent bucket tests were done for both receivers. Three 3 separate tests for the Javad was also obtained and 6 individual tests for the GS10. The postprocessing of the data received from the receivers was carried out using a software package LEICA Geo Office. It was used to post-process kinematic data acquired with a Trimble R8 receiver. The NMEA data obtained from the mobile and stationary kinematic techniques using the GS10 and Triumph-1 receivers were also processed in MatLab to create various plots. MatLab was also used to generate plots for the post process kinematic results from the R8 receiver. The NMEA data for the bucket test were also analyse and processed in MatLab to generate plots for bucket on time and time to first fix versus the number of satellites and solution type.

\section{MOBILE KINEMATIC RESULTS AND ANALYSIS}

\subsection{GPS + GLONASS}

When figure 1 (a) and (b) are compared to figure 2 (a) and (b) correspondingly, it is clear that the GS10 performed better on the mobile kinematic test using both GPS and GLONASS constellations. Figure 2 (a) shows that the GS10 had a more precise height which resulted in a more refine 3D position. When figure 1 (a) is compared to 2 (b) it also indicates that the GS10 had more RTK solutions than the Javad and in the vegetation cover where the Javad had standalone positioning, the GS10 had DGPS (sometimes a float solution). As a result the GS10 2D perspective is more precise than the Javad. The GS10 only had DGPS and RTK solutions while the Javad had float, SPS and RTK solutions.

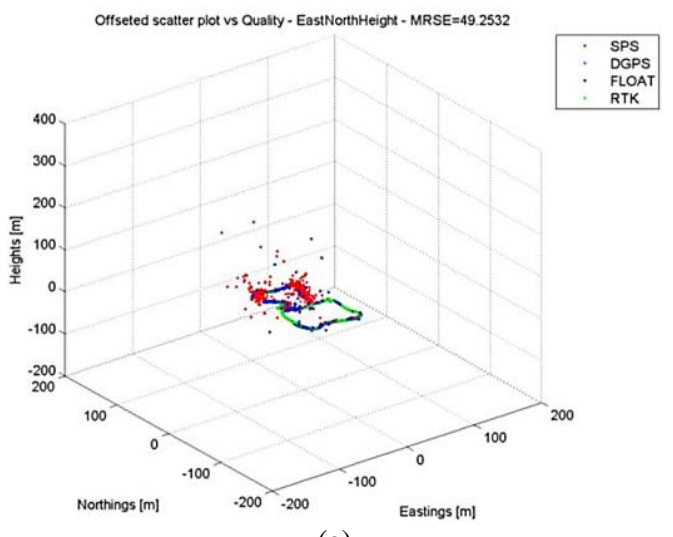

(a)

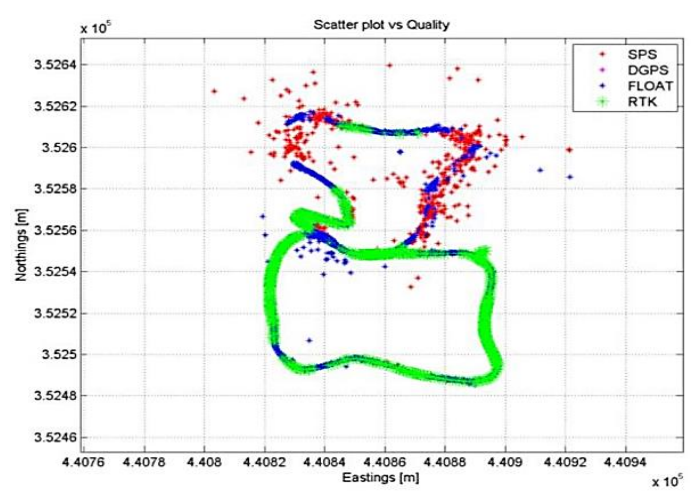

(b)

Figure 1. Mobile Kinematic Results: (a) Javad Mobile Kinematic 3D; (b) Javad Mobile Kinematic 2D.

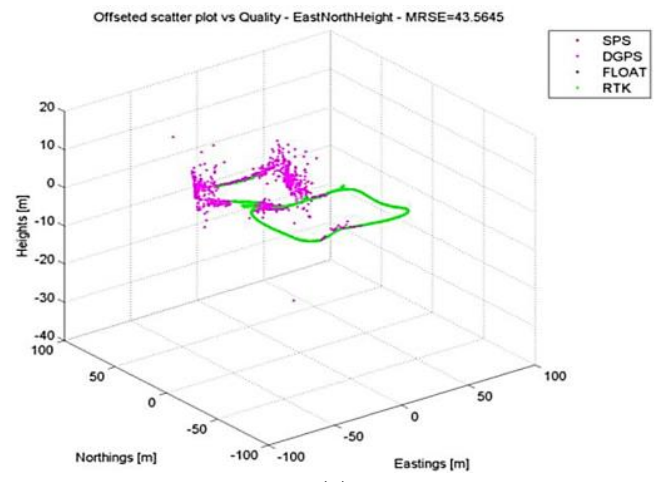

(a)

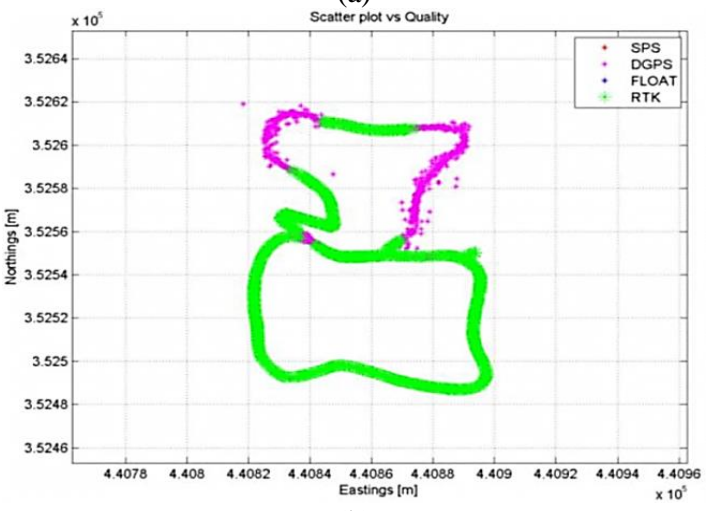

(b)

Figure 2. Mobile Kinematic Results: (a) GS10 Mobile Kinematic 3D; (b) GS10 Mobile Kinematic 2D.

By comparing figure 3 (a) and 3 (b) to figure 4 (a) and 4 (b) respectively, it is evident that both the northing and easting for the GS10 are more precise than the Javad. Hence the GS10 2D precision was better than the Javad. 


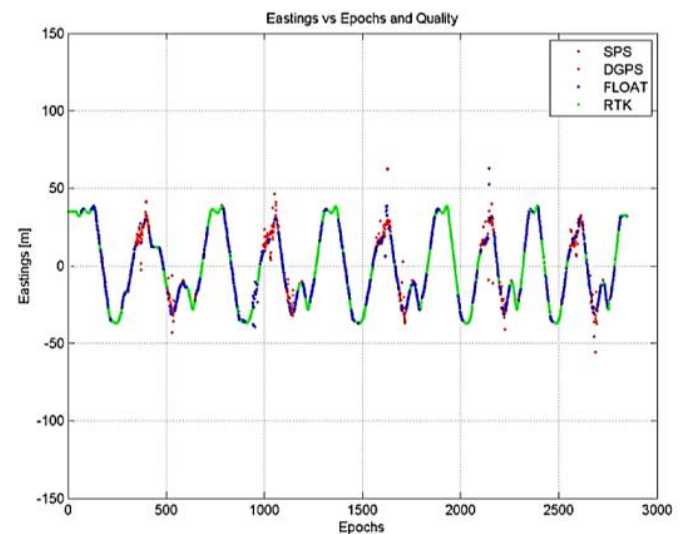

(a)

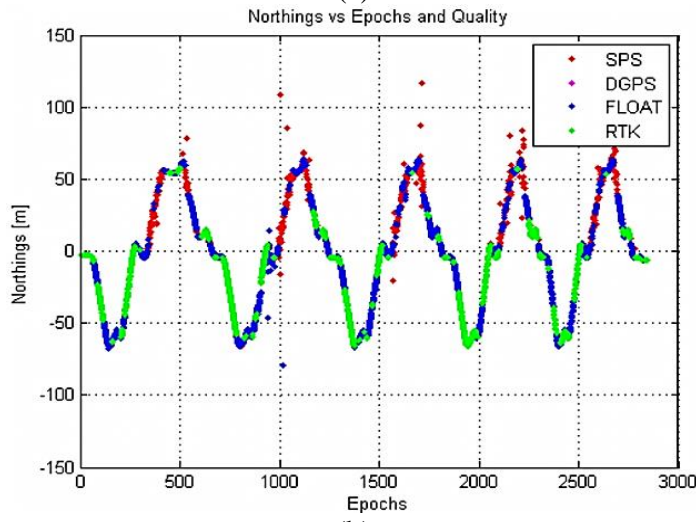

(b)

Figure 3. Javad Mobile Kinematic Results: (a) Easting Time Series; (b) Northing Time Series.

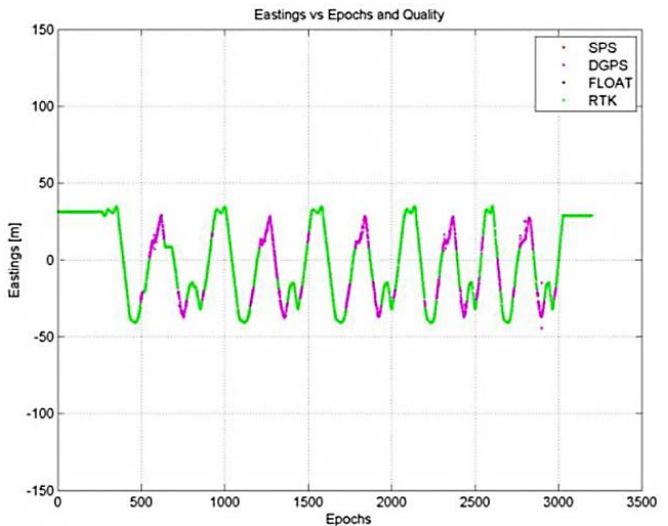

(a)

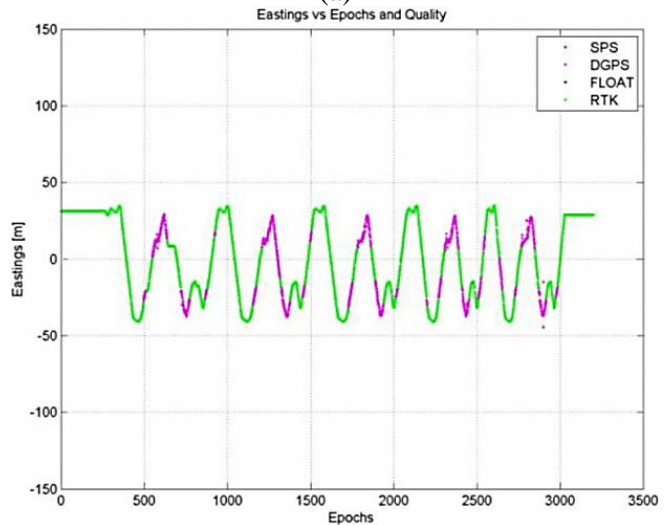

(b)

Figure 4. GS10 Mobile Kinematic Results: (a) Easting Time Series; (b) Northing Time Series.

Figure 6 (a) illustrates that the GS10 HDOP is minimally better than the Javad (figure 5 (a)) in the open area but was undoubtedly better under the vegetation. Figure 5 (b) and 6(b) demonstrates that the satellite availability for both receivers was similar in most instances but the GS10 tracked more satellites in the north east canopy area.

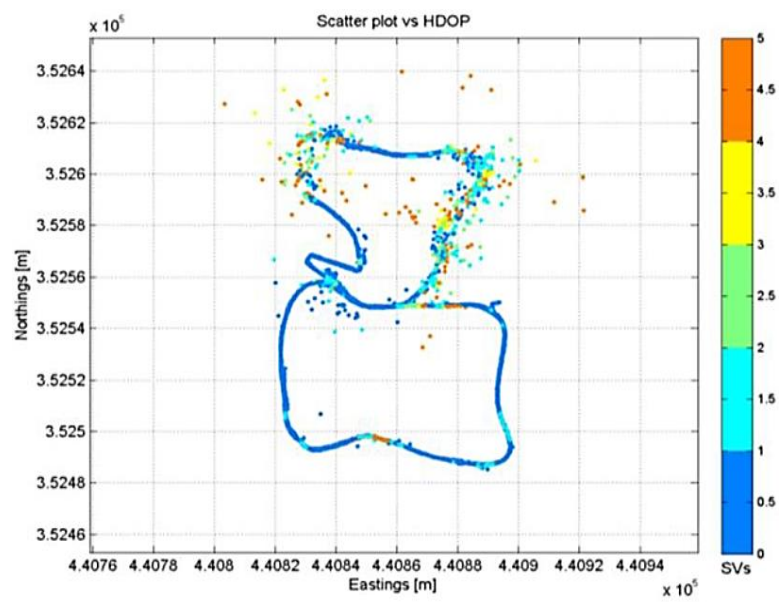

(a)

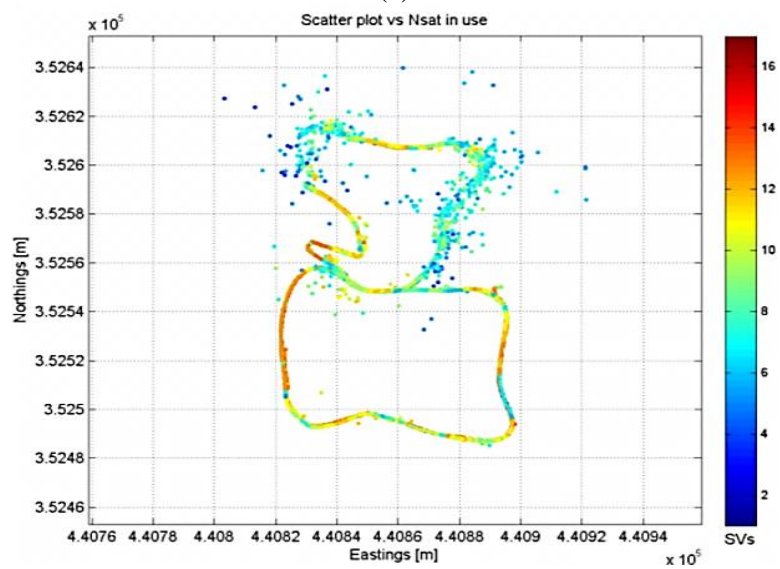

(b)

Figure 5. Javad Mobile Kinematic Results: (a) HDOP vs. 2D; (b) No. SV vs. 2D.

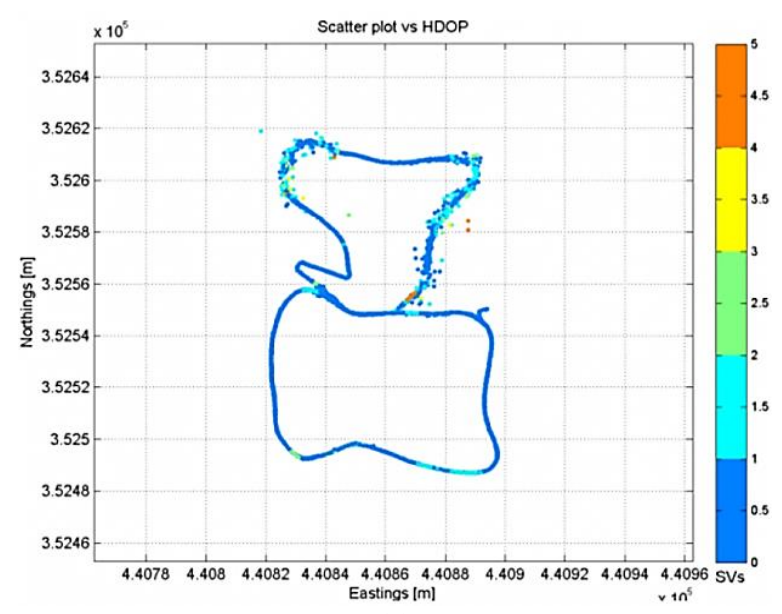

(a) 


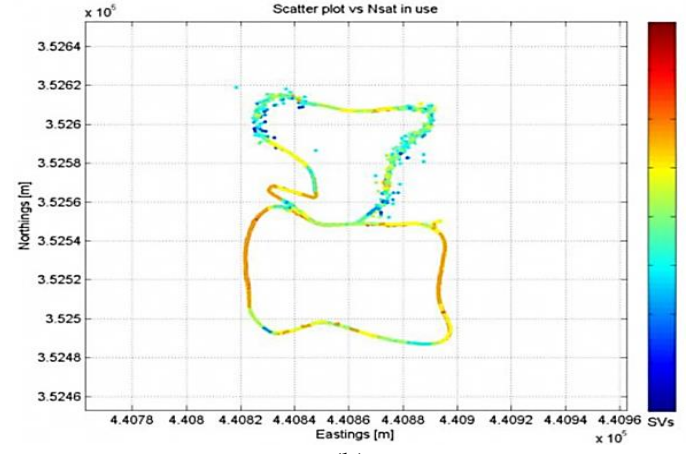

(b)

Figure 6. GS10 Mobile Kinematic Results: (a) HDOP vs. 2D; (b) No. SV vs. 2D

\subsection{GPS}

By comparing figures 7 (a) and 7 (b) with figures 8 (a) and 8(b) respectively, it is evident that the GS10 had the better precision on the mobile kinematic test using only the GPS constellation. Figure 8 (a) demonstrates that the GS10 had a more precise height which resulted in better 3D precision. When figure 7 (b) is compared to 8 (b) it also indicates that the GS10 had more RTK solutions than the Javad and in the vegetation cover where the Javad had standalone positioning the GS10 had DGPS. As a result the GS10 2D perspective is more precise than the Javad. It is worth mentioning that GPS only $2 \mathrm{D}$ and $3 \mathrm{D}$ precesions for Javad seems to be better than GPS+GLONASS 2D and 3D precisions. The GPS only 2D precision for the GS10 had more RTK fixes in the tree tunel (west in figures 2 (b) and 8 (b)) than GPS+GLONASS 2D postioning.

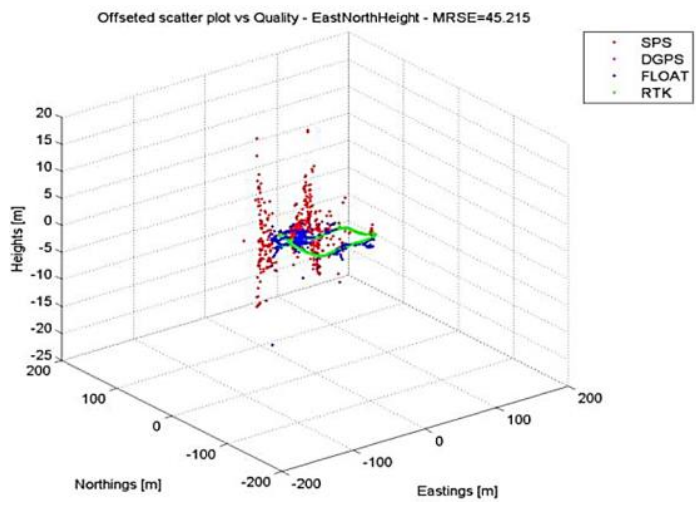

(a)

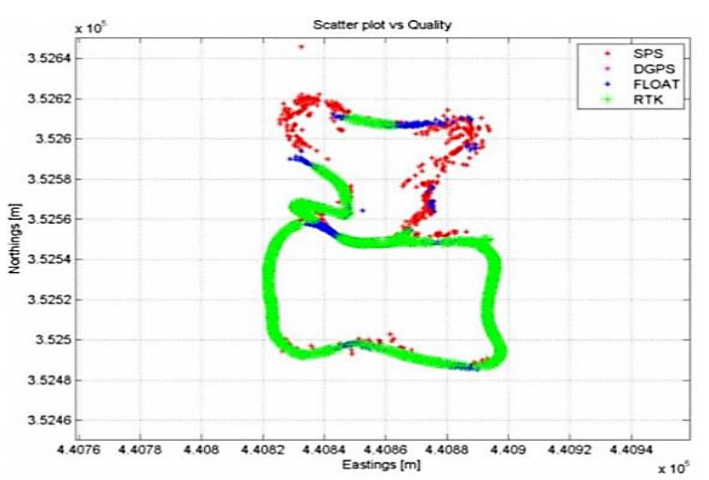

(b)

Figure 7. Mobile Kinematic Results: (a) Javad Mobile Kinematic3D; (b) Javad Mobile Kinematic2D.

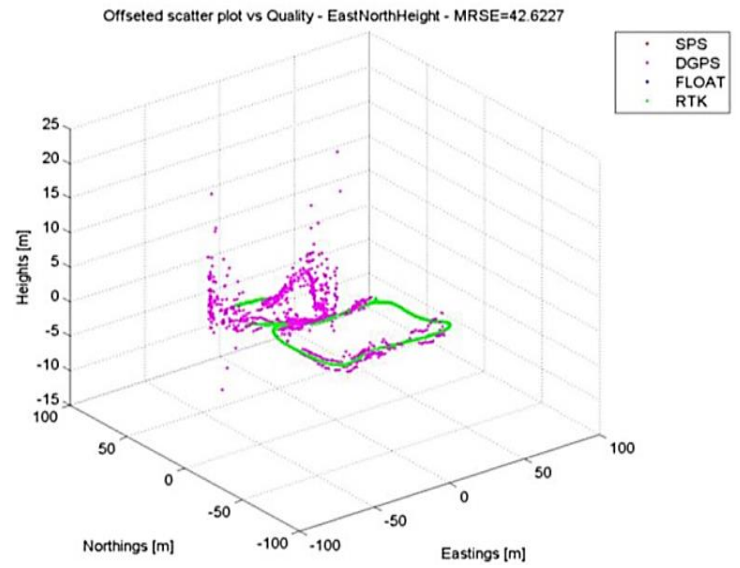

(a)

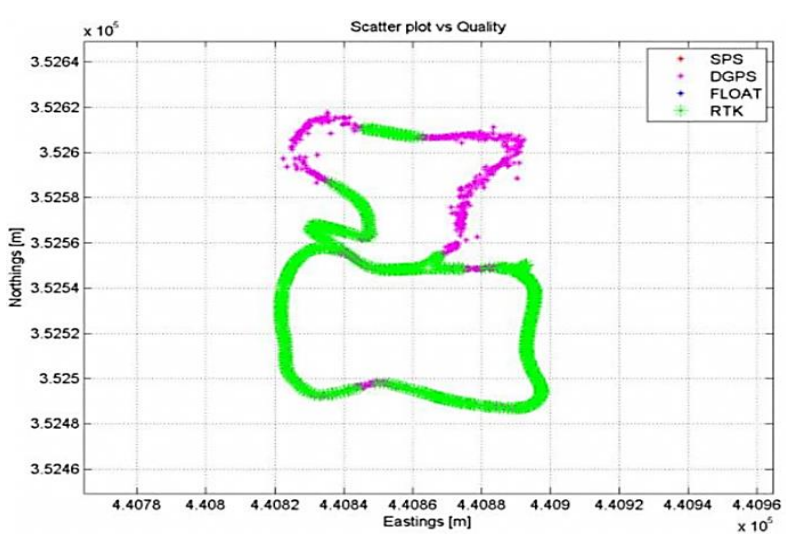

(b)

Figure 8. Mobile Kinematic Results: (a) GS10 Mobile Kinematic 3D; (b) GS10 Mobile Kinematic 2D

The GS10 and Javad easting are generally of the same precision but the northing for the GS10 in marginally better than the Javad (figure 9 (a), 9 (b). 10 (a) and 10 (b)). When figure 11 (a) and 11 (b) are compared the Javad had the better HDOP in some part of the open areas of the track.

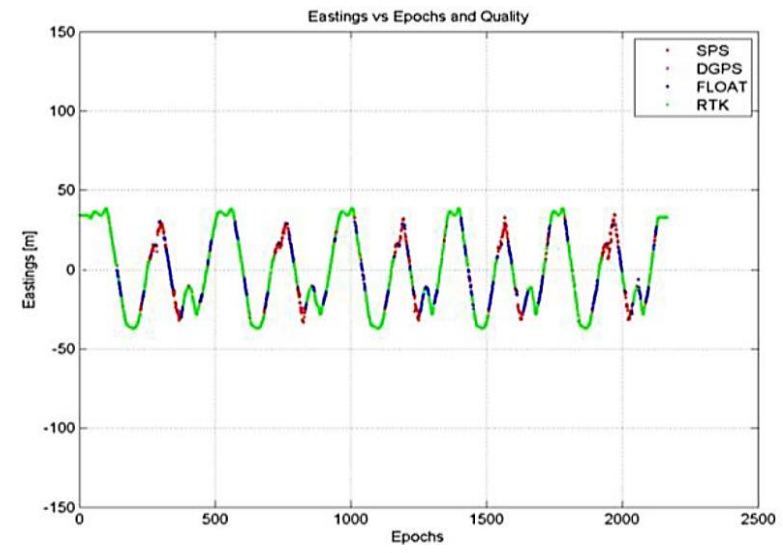

(a) 


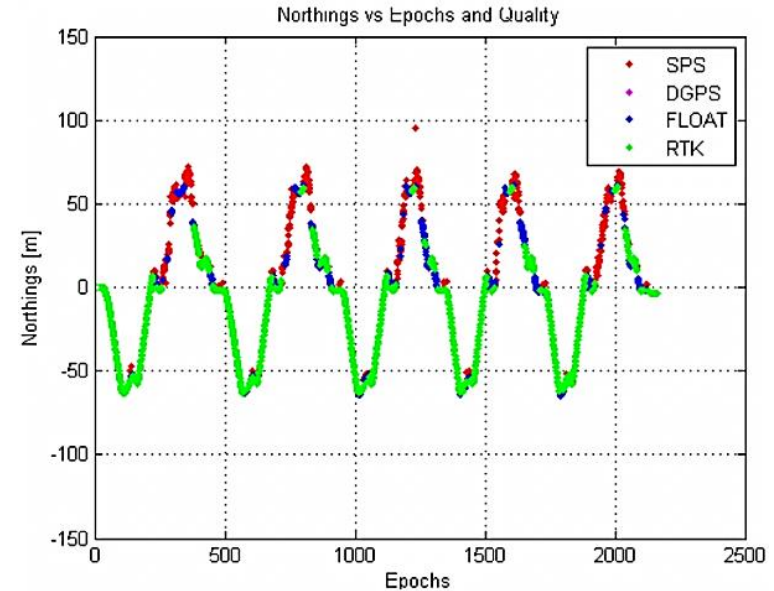

(b)

Figure 9. Mobile Kinematic Results: (a) Javad Easting Time Series; (b) Javad Northing Time Series.

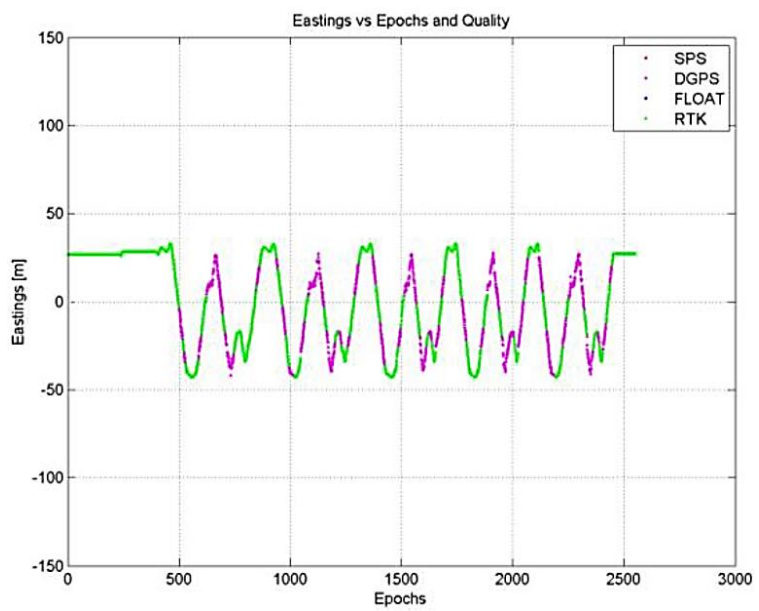

(a)

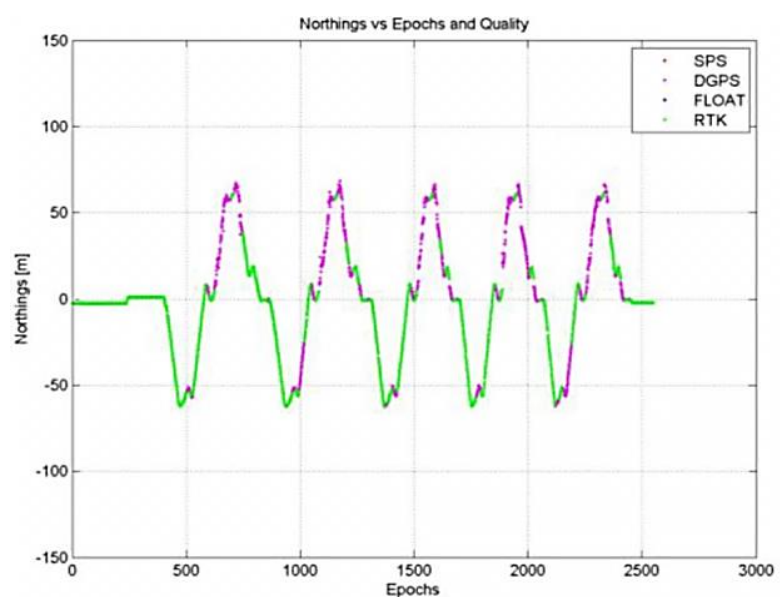

(b)

Figure 10. Mobile Kinematic Results: (a) GS10 Easting Time Series; (b) GS10 Northing Time Series.

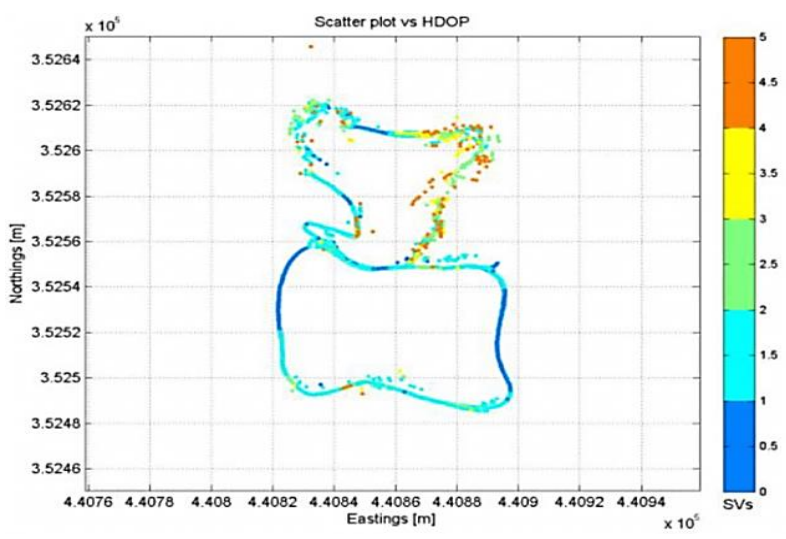

(a)

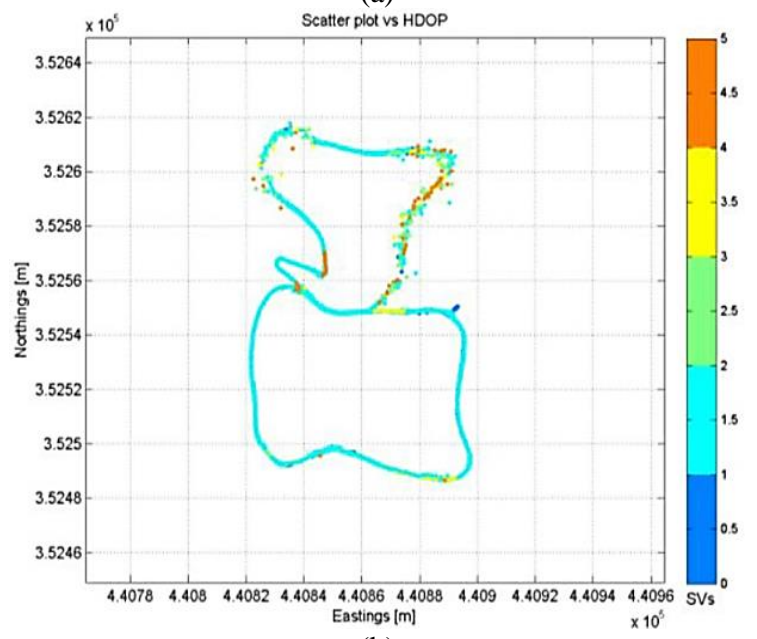

(b)

Figure 11. Mobile Kinematic HDOP vs 2D: (a) Javad; (b) GS10.

\section{KINEMATIC BUCKET TEST RESULTS AND ANALYSIS}

\section{1. Recovery Time}

For the open site, when the bucket on the GS10 lost communication and satellite lock instantaneously, while the Javad had float solution during the bucket-on time. However as indicated in table 1 the GS10 had a faster recovery time in the open environment.

\begin{tabular}{|l|l|l|l|}
\hline Receivers & Results & Open Site & Under Tree \\
\hline Leica & Average, sec & 12 & 417 \\
\hline Javad & Average, sec & 35 & 255 \\
\hline Leica & $\begin{array}{l}\text { First Sample } \\
\text { Fixed, sec }\end{array}$ & 15 & 1273 \\
\hline Javad & First Sample & 26 & 186 \\
& Fixed, sec & & \\
\hline
\end{tabular}

Table 1. Bucket Test Recovery Time.

Out of the 20 samples there was only sample which the Javad recovery time was faster than the GS10 (figure 20). Regarding the vegetation site there were only three synchronized tests during which the Javad recovered 2 times before the GS10 and seems to have a faster average recovery time. However these results are not conclusive because as time progressed we got 3 separate tests for the Javad and 6 for the GS10 and most of 
GS10 separate samples recovery times were less than 3 minutes. For both the open and vegetation bucket tests sixteen satellites were used after the bucket was removed to attain the first fix solution. We also noticed that when the GS10 had a fix it lasted longer than the Javad. We were informed that this was due to the different algorithms. The GS10 algorithms perform redundancy check by comparing different measurement and will not produce a fix if the measurements did not correlate. Hence it may take longer to get a fix but will also maintain it longer. This redundancy checking may have also contributed to the GS10 static solution in the canopy environment not being fixed.
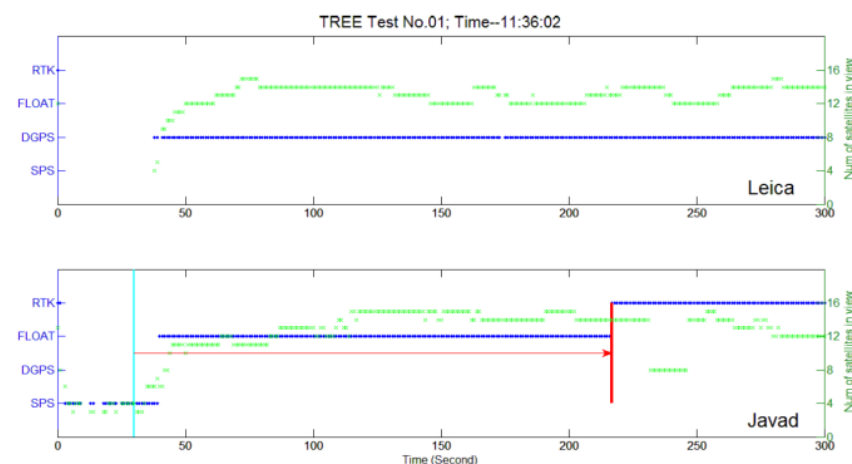

Figure 12. Open Area Bucket Test Sample 1
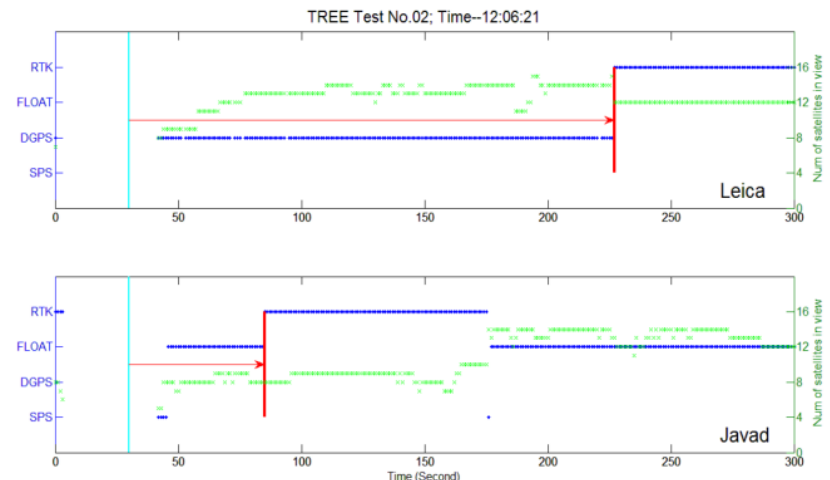

Figure 13. Open Area Bucket Test Sample 2
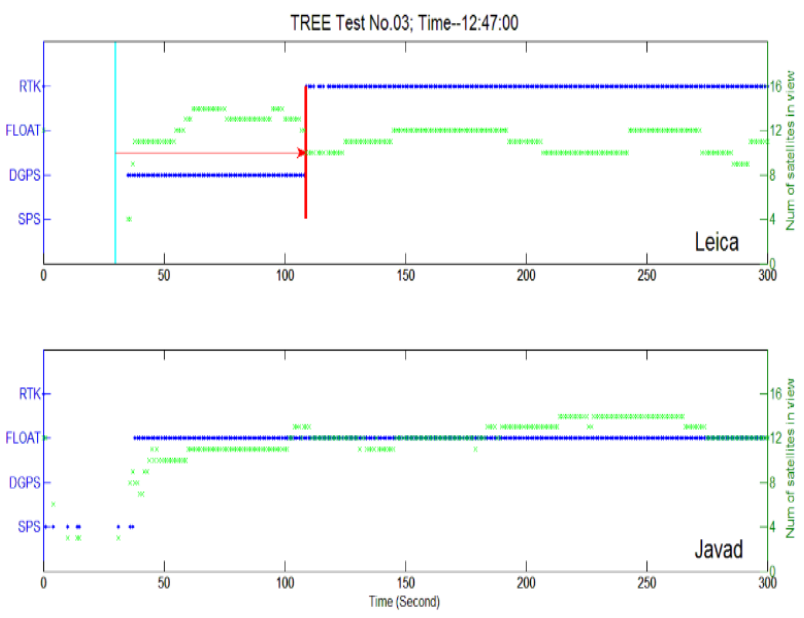

Figure 14. Open Area Bucket Test Sample 3
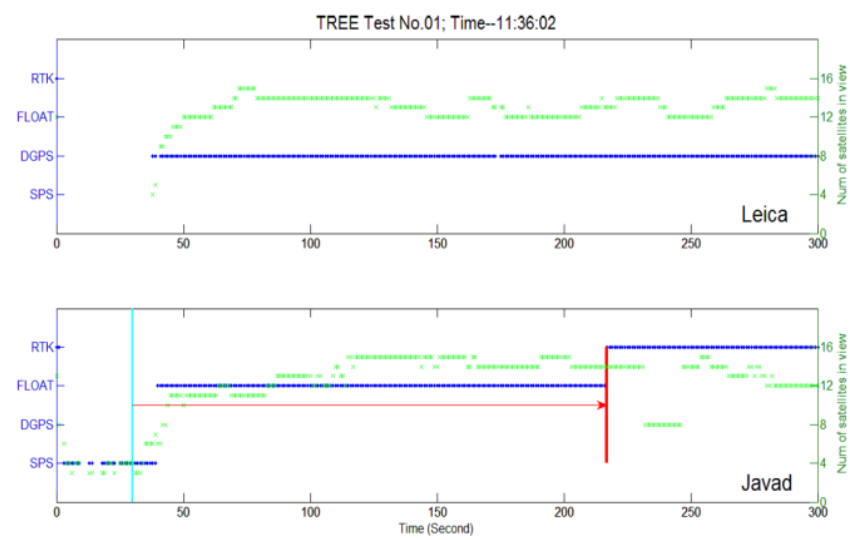

Figure 15. Vegetation Area Bucket Test Sample 1
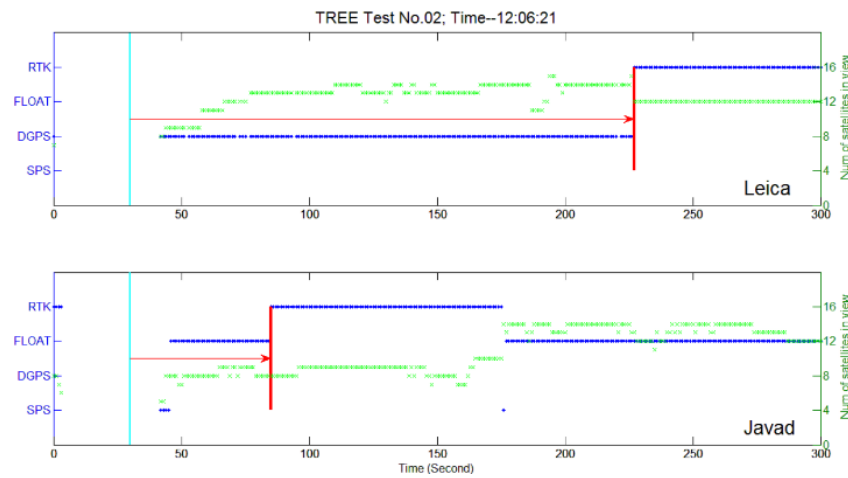

Figure 16. Vegetation Area Bucket Test Sample 2
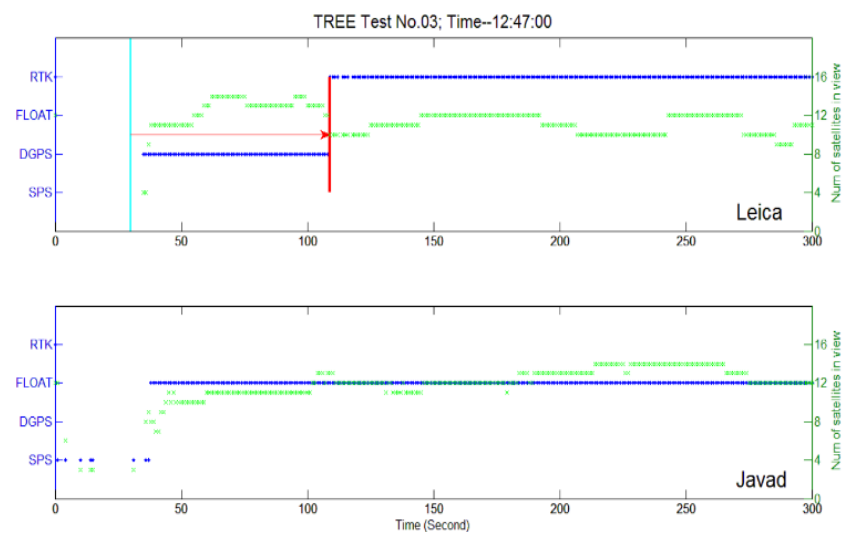

Figure 17. Vegetation Area Bucket Test Sample 3

\subsection{Coordinates after First Fix (Open Site)}

The GS10 had the better average for horizontal solution. However, an average the Javad height and 3D solutions were better than the GS10. 


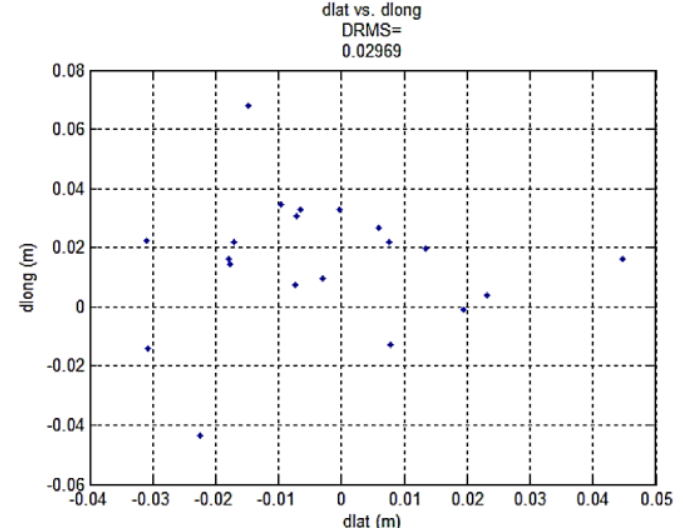

(a)

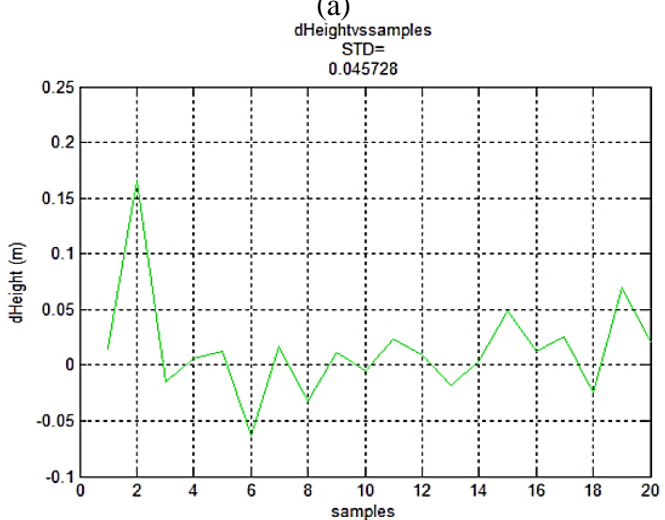

(b)

Figure 18. Coordinates differences: (a) Leica 2D Open Bucket test; (b) Leica Height Open Bucket test.

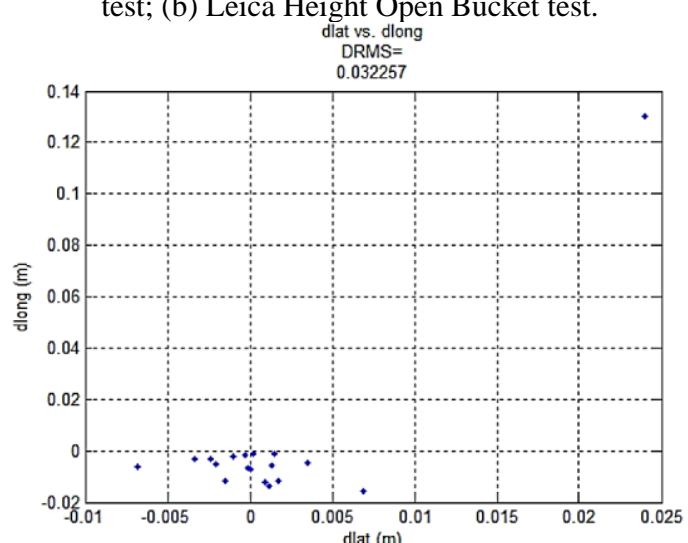

(a)

Heightvssamples

0.0078786

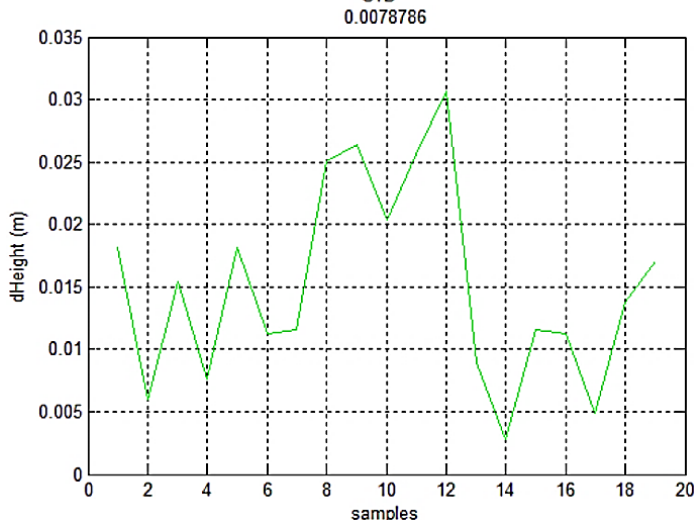

(b)

Figure 19. Coordinates differences: (a) Javad 2D Open Bucket test; (b) Javad Height Open Bucket test.

\subsection{Coordinates after First Fix (Canopy Site)}

The coordinates after first fix on the vegetation site are similar to those on the open site. That is the GS10 had the better average for horizontal solution and the Javad height and 3D solutions were better than the GS10. However these results are not definite since only 3 samples were executed concurrently in the vegetation environment.

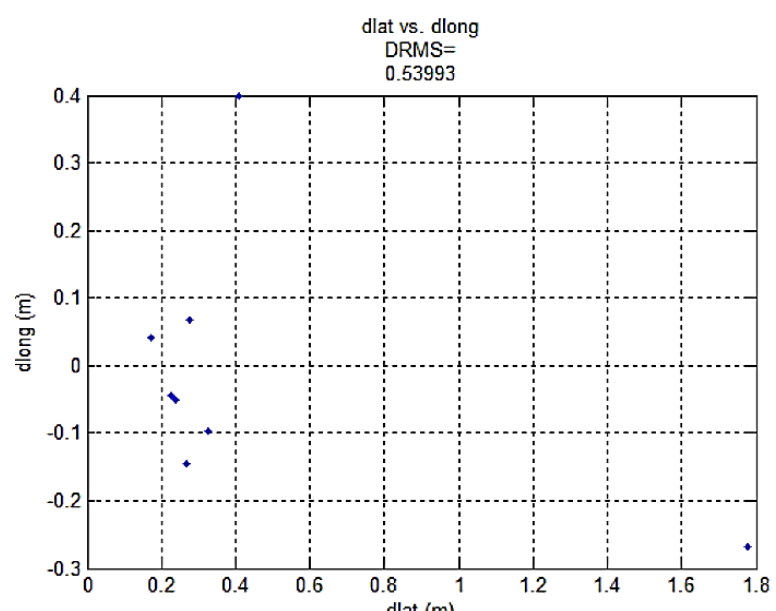

(a)

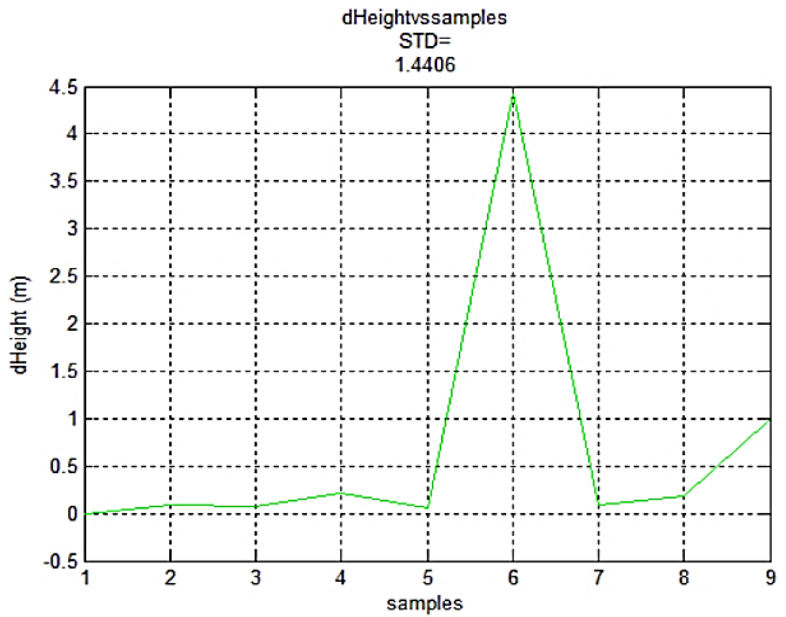

(b)

Figure 20. Coordinates differences: (a) Leica 2D Open Bucket test; (b) Leica Height Open Bucket test.

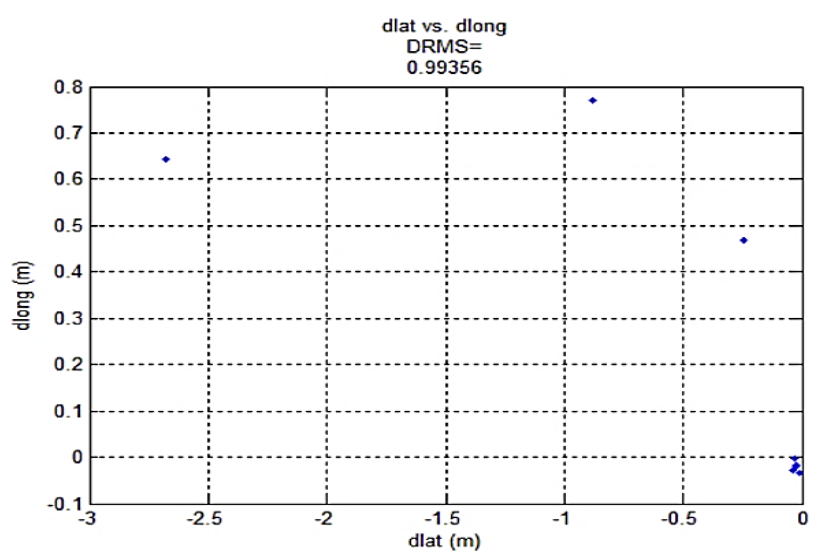

(a) 


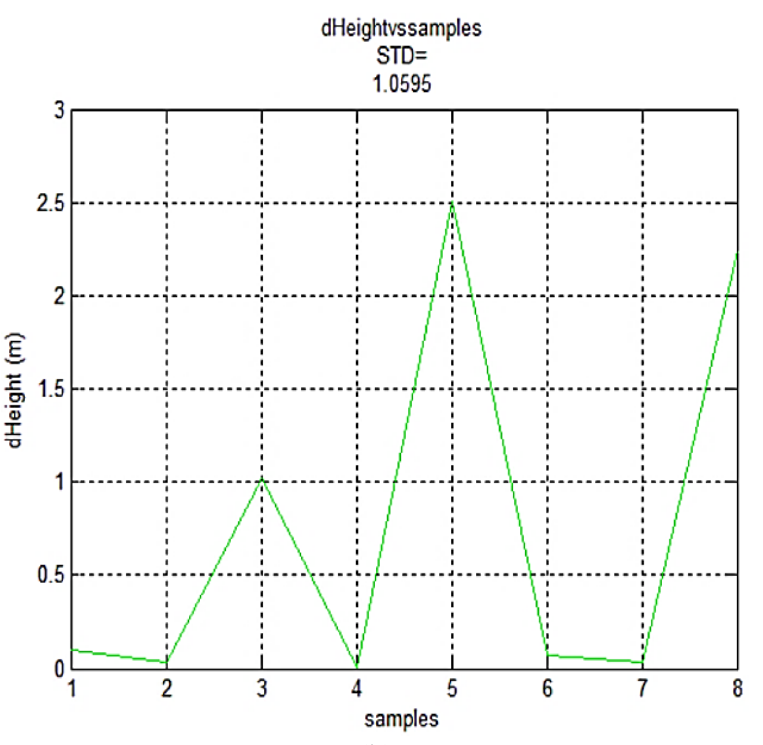

(b)

Figure 21. Coordinates differences: (a) Javad 2D Open Bucket test; (b) Javad Height Open Bucket test.

\section{CONCLUSION}

This study aims to analyze the accuracy assessment of various GNSS processing strategies under various conditions. In concluding it is evident that for the mobile kinematic tests the GS10 dominated when both GPS and GLONASS constellations were used. It was also the better receiver when only satellites from the GPS constellation were used. The Javad was the only receiver capable of tracking GLONASS only satellites. However it was imposible to obtained fix solutions due to GLONASS satellites signals being frequency modulated.

The R8 performed the best on the canopy site in terms of position quality and fix solution but the Javad had the better precision. The GS10 performed the worst on the vegetation site in terms of fix solution and precision. The GS10 also had the worst agreement for horizontal, height and 3D solution between dual and single frequency processing on the canopy site. The R8 on the other hand horizontal, height and 3D solutions between dual and single frequency results was the most consistent. Based on the result of estimation on the open site, we can conclude from the comparation that the GS10 horizontal solution between dual and single frequency processing was the most consistent but the Javad 3D was the most stable. In the open environment the GS10 precision was significantly the best, while the Javad precision was the worst.

Regarding the bucket test, the GS10 had a faster recovery time in the open but it is difficult to state which receiver performed better in the vegetation cover. Thus, based on the results, it also shows that the presence of a good satellite is also limited by the survey conditions, affecting the use of GNSS in crowded urban environments.

\section{ACKNOWLEDGEMENTS}

This research has been/was/is funded by the Science Committee of the Ministry of Education and Science of the Republic of Kazakhstan (Grant No. AP09058620 on the topic: «Web-GIS development based on complex geodynamic monitoring data for Kazakhmys LLP deposit field»)- duration 3 years, 54000000 KZT generally (1800000 KZT per year including everything)

\section{REFERENCES}

Grejner-Brzezinska, D.A.; Kashani, I.; Wielgosz, P. 2005. On accuracy and reliability of instantaneous network RTK as a function of network geometry, station separation, and a data processing strategy. GPS Solut, 9, 212-225. doi: 10.1007/s10291-005-0130-1

Hofmann-Wellenhof, B.; Wasle, H.L., 2008. GNSS - Global Navigation Satellite Systems: GPS, GLONASS, Galileo and More, New York: Springer Wien

Hsu L.-T., 2018. Analysis and modeling GPS NLOS effect in highly urbanized area. GPS solutions, vol. 22 , no. 1 , pp. 7

Jansson, P.; Persson, C.G., 2013. The effect of correlation on uncertainty estimates - with GPS examples. Journal of Geodetic Science, 3(2): 111-120. doi: 10.2478/jogs-2013-0016

Jaud, Š., Donaubauer, A., Heunecke, O. \& Borrmann, A., 2020. Georeferencing in the context of building information modelling. In: Automation in Construction, 118:103211.

Karaim M., Elsheikh M., Noureldin A., 2018. GNSS Error Sources. Multifunctional Operation and Application of GPS, pp. 69-85

Kubo N. and Dihan C., 2014. Performance evaluation of RTKGNSS with existing sensors in dense urban areas. J. Geodesy Geomat. Eng, vol. 1, pp. 18-28.

Leick, A.; Rapoport, L.; Tatarnikov, D., 2015. GPS Satellite Surveying. Wiley\&Sons

Li B.; Shen Y.; X, P. 2008. Assessment of stochastic models for GPS measurements with different types of receivers. Chinese Sci Bull, 53, Issue 20, 3219-3225. doi: 10.1007/s11434-0080293-6

Parkinson, B.W.; Spilker J. J. Jr, 1996. Global Positioning System: Theory and Applications Volume I, American Institute of Aeronautics and Astronautics, Washington.

Satirapod, C.; Wang, J. 2000. Comparing the Quality Indicators of GPS carrier phase observations. Geomatics Research Australasia, 73: 75-92.

Smith P. 2014. BIM Implementation - Global Strategies, Procedia Engineering, Vol. 85, p. 482-492, ISSN 1877-7058, https://doi.org/10.1016/j.proeng.2014.10.575

Wang, J.; Lee, H.K.; Lee, Y.J.; Musa, T.; Rizos, C. 2005. Online Stochastic Modelling for Network-Based GPS RealTime Kinematic Positioning. Journal of Global Positioning Systems, Vol. 4, No. 1-2: 113-119.

Wang, L.; Li, Z.; Zhao, J.; Zhou, K.; Wang, Z.; Yuan, H. 2016. Smart Device-Supported BDS/GNSS Real-Time Kinematic Positioning for Sub-Meter-Level Accuracy in Urban LocationBased Services. Sensors, 16, 2201. https://doi.org/10.3390/s16122201

Zhu J.,Wu P., 2021. A Common Approach to Geo-Referencing Building Models in Industry Foundation Classes for BIM/GIS Integration. 